Musées, Patrimoine et Culture scientifiques et techniques

$190 \mid 2020$

juillet-août 2020

\title{
Hommage à Yves Jeanneret - Un chercheur et un penseur de premier plan des théories de la communication disparaît
}

Jean Davallon, Daniel Jacobi, Baudouin Jurdant et Joëlle Le Marec

\section{(2) OpenEdition}

Édition électronique

URL : https://journals.openedition.org/ocim/4001

DOI : 10.4000/ocim.4001

ISSN : 2108-646X

Éditeur

OCIM

\section{Édition imprimée}

Date de publication : 1 juillet 2020

Pagination : 30-32

ISSN : 0994-1908

\section{Référence électronique}

Jean Davallon, Daniel Jacobi, Baudouin Jurdant et Joëlle Le Marec, « Hommage à Yves Jeanneret - Un chercheur et un penseur de premier plan des théories de la communication disparaît », La Lettre de I'OCIM [En ligne], 190 | 2020, mis en ligne le 01 juillet 2021, consulté le 17 juillet 2021. URL : http:// journals.openedition.org/ocim/4001; DOI : https://doi.org/10.4000/ocim.4001

Ce document a été généré automatiquement le 17 juillet 2021

Tous droits réservés 
Hommage à Yves Jeanneret - Un chercheur et un penseur de premier plan des théories de la communication disparaît

Jean Davallon, Daniel Jacobi, Baudouin Jurdant et Joëlle Le Marec 
Yves Jeanneret, en 2011, animant les Rencontres du Celsa Le " public jeune ", promesse ou mirage ? Copies d'écran de la captation vidéo.

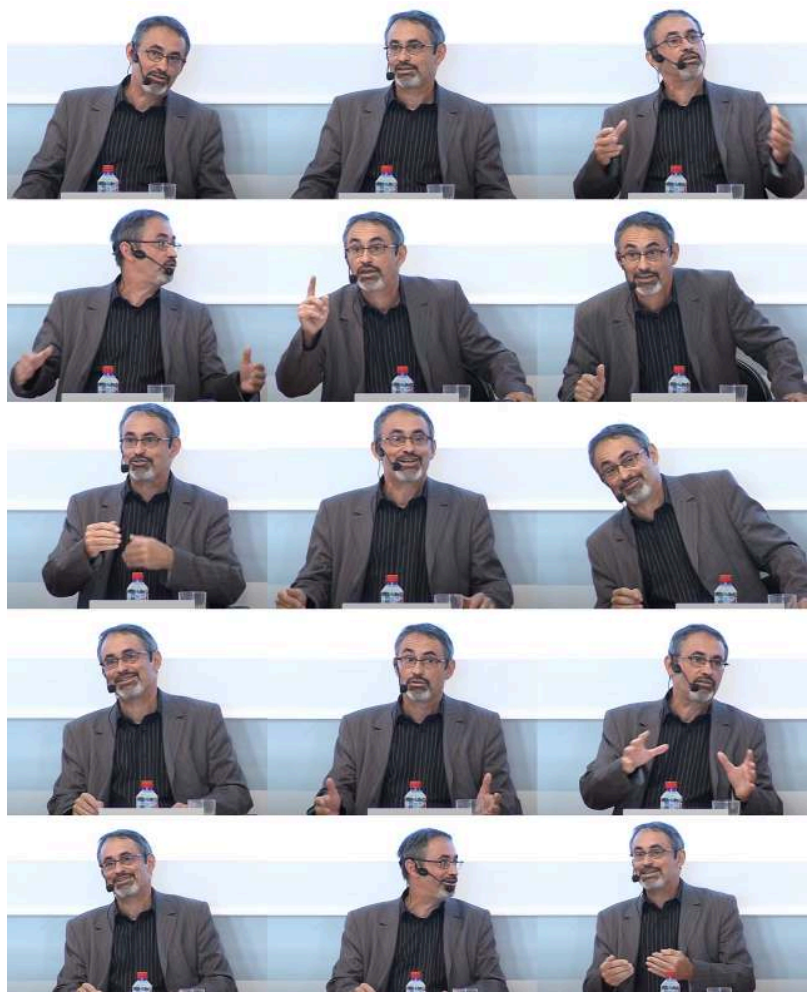

(c) Images : Celsa université Paris-Sorbonne ; photomontage : Ocim/FL

125 mai 2020. Les messages affluent: Yves Jeanneret est emporté par la maladie. Nous le savions très affaibli. Mais l'annonce de l'évènement est pour nous un choc. Ce n'est pas seulement la perte d'un collègue ou d'un ami. Sa disparition est aussi celle d'un excellent chercheur et d'un penseur de premier plan des théories de la communication. De Paris à Lille, puis de Paris à Avignon et retour dans la capitale : à chaque fois il a creusé le sillon. Une trace profonde, ouverte, fédérant autour de lui une communauté de collègues et de jeunes chercheurs. Au sortir de l'École Normale supérieure, il se passionne pour l'œuvre de Romain Rolland. Il enseigne quelques années avant d'être nommé dans une école d'ingénieurs (EN Sup. des télécommunications). Lui, un littéraire pur, y développe un intérêt grandissant pour la culture scientifique et technique. En 1994, il publie Écrire la Science (PUF, 1994). Certes Baudouin et Daniel ont déjà défriché le terrain de la socio-diffusion de la culture scientifique et technique ; mais en décrivant finement la complexité des figures de discours de ce secteur spécifique de la communication dans les médias, il démontre qu'elle construit une rhétorique singulière.

2 À l'université de Lille, il développe ce qui deviendra un ensemble théorique de premier plan en sciences de l'information et de la communication: pour étudier les médias informatisés à l'aide d'une sémiotique soucieuse de la matérialité et de la densité des objets comme de la diversité des pratiques qui leur donnent vie. L'ouvrage collectif Lire, écrire, récrire. Objets, signes et pratiques des médias informatisés (Centre Pompidou, 2003) en est l'aboutissement. Toutes celles et tous ceux qui ont participé aux innombrables apprentissages, aux dialogues ou controverses, ont construit avec lui une manière de pratiquer la recherche collectivement, dans un espace assez égalitaire pour 
supporter différentes manières d'interpréter entre autres les "écrits d'écran ». La sémiotique des écrits et l'enquête ethnographique ont permis d'approcher la culture et les médias d'une façon nouvelle. À Lille aussi, au fil de ses séminaires, se partagent et se transmettent quantité de questions relatives à la prolifération des termes préfabriqués. Tous les nouveaux mots-valises comme «technologies de la communication", " numérique ", «transparence ", « interactivité », etc., y sont démontés. Yves propose et enseigne avec un lexique soigneux, exigeant, constamment renouvelé, pour garder la liberté de penser librement les objets de la communication, qu'ils soient industriels ou marchands.

3 Une de ses grandes entreprises a été de comprendre ce qu'il a nommé la «trivialité ». Après les années 2000, portant un regard sur ce qui traverse tout son travail, il entreprend de lui consacrer un, puis deux ouvrages: Penser la trivialité (HermèsLavoisier, 2008) et Critique de la trivialité (Éditions Non Standard, 2014). Auxquels il faut ajouter son dernier ouvrage La fabrique de la trace (ISTE Éditions, 2019) qui en discute le fondement. Ces ouvrages illustrent la force d'une démarche où la précision de la définition oblige à changer de point de vue. En effet, prendre en compte la trivialité oblige à ne plus regarder la culture à partir des objets qui la compose (les œuvres littéraires, les émissions, les films, les expositions ou les objets de patrimoine), mais à porter toute son attention sur sa circulation et ses effets. Pour lui, l'important dans cette circulation sont les altérations - modifications, mais aussi ajouts, réécritures, commentaires, emprunts, usages, traductions dans un autre média - qui produisent des "êtres culturels». Ces derniers sont ainsi des mixtes d'objets, de représentation et de pratiques dont la littérature, les documentaires, les médias informatisés ou le patrimoine matériel ou immatériel sont des exemples.

Dans le monde de la CSTI et particulièrement des musées - où il a rejoint Joëlle, puis Jean et Daniel à Avignon et entre autres, en partenariat avec l'Ocim - il contribue à faire de la recherche un acteur de premier plan au service d'une demande sociale spécifique. Nous nous souvenons tous de ces journées qu'il a marquées de sa présence. Invité comme conférencier et personnalité reconnue, il arrive dès le début de la séance. Il s'assoit, sort son carnet et son stylo plume. Les orateurs se succèdent pour présenter une contribution. Il écrit sans arrêt, participe au jeu des questions qui suivent les interventions. À la fin de la journée, on l'invite à faire une synthèse de la journée. Yves se lève. Sort son carnet. Il parle sans vraiment lire ses notes. L'écoute est forte et l'exposé lumineux au point de rendre chacun de nous plus lucide et plus intelligent...

\section{RÉSUMÉS}

Le décès d'Yves Jeanneret en mai dernier a annoncé la fin d'un dialogue avec un brillant chercheur, professeur, penseur. La discussion et la réflexion qu'il a initiées depuis de nombreuses années en revanche, continuent et perdurent.

Jean Davallon, Daniel Jacobi, Baudouin Jurdant et Joëlle Le Marec reviennent sur son apport aux sciences de l'information et de la communication. 
INDEX

Mots-clés : chercheur ; organisation de l'enseignement supérieur 